nals that publish original research have been around for a long time, this is the first to devote itself to new methods, and

The first volume covers a range of subjects and includes three excellent technological reviews on quantitation of cell proliferation, whole-body autoradiography and in situ hybridization. The original papers are roughly divided between in vivo and in vitro methods and new analytical techniques. Not all of the methods described are brand new, but they do represent important advances. A. Barlow et al., for example, have taken a second look at an in vitro test that assesses the corrosive potential of chemicals. This is carried out by measuring changes in transcutaneous electrical resistance, but the method is that is why it fills a gap.

flawed because organic solvents and surfactants that are not corrosive cause similar changes. Simply swapping the standard sodium chloride electrolyte with magnesium sulphate reduces the false positives from 26 to 9 per cent. Not great science perhaps, but a considerable improvement on an important test. In its first year, the journal has had a 27 per cent rejection rate and the time from receipt of a paper to its publication has averaged three-and-a-half months.

For a new journal, the quality of the original papers is good and is bound to improve as the journal becomes better known by toxicologists.

T. A. Connors is in the MRC Toxicology Unit, MRC Laboratories, Woodmansterne Road, Carshalton, Surrey SM5 4EF, UK.

\section{Burgeoning biocontrol}

\section{Keith Sunderland}

Biocontrol Science and Technology. Editor-in-chief Chris C. Payne. Carfax. $4 / y r$. US and Canada \$280, Europe $£ 140$, elsewhere $£ 160$ (institutional); US and Canada \$99, Europe $£ 46$, elsewhere $£ 57$ (personal).

Biological Control. Editors-in-chief Raghaven Charudattan, W. Joe Lewis, Harry K. Kaya and Charlie E. Rogers. Academic. 4/yr. US and Canada \$146, elsewhere $\$ 166$.

THESE two new journals, launched in 1991 , seem at first sight to be in competition for the same market. I looked for signs of 'niche differentiation' in their first volumes, but found little evidence of any. Both have responded to the need to collect together biocontrol papers previously scattered in a wide range of journals, and both can justifiably claim to be multidisciplinary journals with high scientific and editorial standards and a good quality of production. There are some minor differences in the facilities offered: Biocontrol Science and Technology (BST) has a contents section and author index for each volume, whereas Biocontrol has, in addition, a subject index and list of referees and will publish symposium proceedings and letters to the editor. On the other hand, $B S T$ has a regular review slot and accepts short communications for rapid publication.

Perhaps the main difference lies in geographical coverage; $B S T$ has lived up to its promise to be truly international (no more than 5 out of the 27 members of the editorial board come from a single country and no more than 28 per cent of the 28 papers in the first volume emanate from one country). Biocontrol makes no claim to be international; 21 out of 33 members of the editorial board live in the United States and 87 per cent of the 47 papers published in the first volume are also from that country.

Both journals have an extensive remit, covering the theory and application of biological control of animal pests (including pests of plants and arthropod pests of man, our stored products and domestic animals) and of diseases and weeds; this is a strength, admitting the possibility of cross-fertilization of ideas between subdisciplines. A good balance of papers has been achieved, whether judged in terms of type of biocontrol agent (including microbes, nematodes, arthropods and molluscs), target pest or category of study (including the biology, ecology, physiology, genetic improvement, culturing, quality control, application and effectiveness of control agents). Currently, Biocontrol has slightly more emphasis than BST on the ecological aspects of biocontrol.

The field of biocontrol is growing rapidly, driven mainly by the global trend towards reduction in the use of chemical pesticides and the need to develop substainable and environmentally acceptable alternative strategies of pest control. And the accelerating spread of pest species beyond their countries of origin demands greater allocation of resources to the study of biological control. Given this situation, it seems likely that there will continue to be more than enough material to sustain both of these journals.

Keith Sunderland is in the Microbiology and Crop Protection Department, Horticulture Research International, Littlehampton, West Sussex BN17 6LP, UK.

\section{Seeds of success}

\section{Robin Probert}

Seed Science Research. Editor M. Black. CAB International. 4/yr. US \$214, elsewhere $£ 116$.

SEEDS provide 55 per cent of the daily per capita energy requirement of humankind, excluding their contribution to the nutrition of livestock. The importance of seeds is reflected in the amount of research devoted to them. For example, a recent literature search revealed more than 2,400 reports in the past 21 years alone in which seed germination and dormancy were linked to temperature - a subject reflecting only a small part of the spectrum of seed-related issues.

Because of the convenience of seeds, researchers often turn to them for a model system for investigating central issues in plant science. In his opening address to the Fourth International Workshop on Seeds (July 1992, Angers), C. M. Karssen described this activity as "science with seeds", as distinct from "seed science", which may be defined as

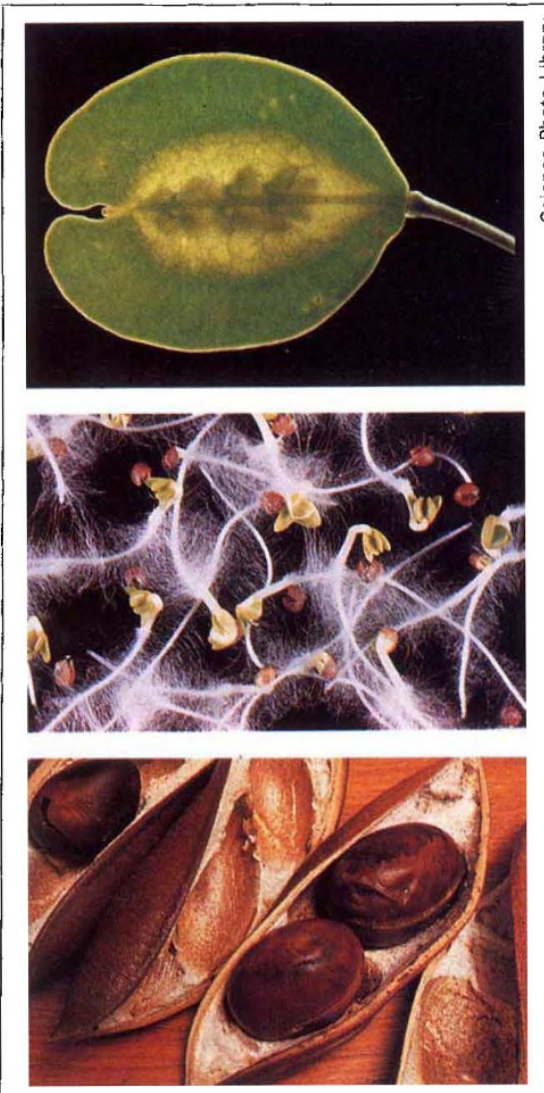

From top to bottom: seed pod of the fleld penny cress, Thlaspl arvense; germination of clover seeds, Trifollum sp.; and seeds of the Moreton Bay chestnut, Castanospernum australe, from the ralnforests of Australla. 